\title{
Subsídios para uma caracterização do discurso institucional
}

Dilson Ferreira da Cruz

- Doutor e mestre em Semiótica e Linguística Geral pela Universidade de São Paulo (USP)

- Autor de 0 éthos dos romances de Machado de Assis: uma leitura semiótica (São Paulo: Edusp, 2009); Trinta crônicas irreverentes - Machado de Assis (São Paulo: Disal, 2007); Estratégias e máscaras de um fingidor - a crônica de machado de Assis (São Paulo: Nankin, 2002)

- Tradutor de diversos títulos na área de ciências humanas (francês / português)

- Coordenador da área de planejamento e gestão da informação do Tribunal de Contas do Município de São Paulo

- Bacharel em Ciências Econômicas pela USP

-dfc70@hotmail.com 
Este texto é uma tentativa de caracterizar o discurso institucional unicamente por meio do instrumental teórico da semiótica. Objetiva-se ainda esclarecer outra questão: é possível distinguir o discurso institucional de outros tipos de discurso com base apenas na materialidade do texto, isto é, sem recorrer a elementos que lhe sejam exteriores? O resultado obtido com tal caracterização, independentemente de suas virtudes e vícios, não visa ao estabelecimento de uma definição, mas tão somente a um melhor conhecimento das características intrínsecas a esse tipo de discurso.

PALAVRAS-CHAVE: DISCURSO INSTITUCIONAL・SEMIÓTICA • TEXTO INSTITUCIONAL

Abstract

This text intends to characterize institutional speech, through use only of theoretical semiotic tools. It also aims at clarifying another question: is it possible to distinguish the institutional speech from other kinds of discourse, based only on the materiality of the text, i.e., without resorting to external elements? The result obtained with this characterization, irrespective of its virtues and vices, does not aim at establishing a definition, but only at better knowledge of the intrinsic characteristics of this kind of speech.

KEYWORDS: INSTITUTIONAL SPEECH・SEMIOTIC • TEXT

Resumen

Se intenta caracterizar el discurso institucional por medio solamente del instrumental teórico de la semiótica. Su finalidad es también aclarar otra cuestión: ¿Es posible distinguir el discurso institucional de otros tipos de discurso basándose solamente en la materialidad del texto, esto es, sin recurrir a elementos que le sean externos? El resultado obtenido con tal caracterización, independientemente de sus virtudes y vicios, no busca establecer una definición, sino tan sólo conocer mejor las características intrínsecas de este tipo de discurso. 
Q uando se pensa em discurso institucional, uma das primeiras questões que se apresentam é: mas, afinal, o que é discurso institucional? Ou melhor, como definir um discurso institucional dada a multiplicidade de temas que podem ser abordados? Uma primeira - e tentadora - alternativa é definir discurso institucional como aquele que é produzido por uma instituição. Fácil? Nem tanto. É que as perguntas têm o péssimo costume de vir aos pares. No mínimo. A pergunta seguinte então seria: mas...o que é uma instituição? Sem instrumentos confiáveis para definir o que é uma instituição, a semiótica cujo modelo teórico é a base deste artigo - teria que repassar o problema ao direito e perguntar ao ilustre senhor o que é uma instituição. Resolvida a questão? Talvez, mas não sem certo constrangimento, pois nossa ciência acabaria alienando seu direito (e dever) de resposta às ciências jurídicas e, ao final, o critério de classificação seria algo como: é institucional o discurso o que o direito considerar institucional... Ou seja, ao aceitar o parecer jurídico, as ciências que lidam com a linguagem acabariam por dar-se a si próprias um atestado de, digamos, tibieza intelectual, já que para definir uma de suas categorias teve de recorrer a outro ramo do conhecimento...

Contudo, não é apenas o amor próprio ou, vá lá, certo chauvinismo intelectual que nos leva a rejeitar tal definição. Ainda que se aceitasse o socorro do direito, em breve haveria outro problema: o da legitimidade, pois o que ocorreria se a instituição em questão fosse uma falsa-instituição ou se por algum motivo não tivesse legitimidade para produzir o discurso? Embora assuntos relacionados à ontologia, tais como o estatuto jurídico da instância da enunciação não digam respeito à semiótica, entende-se que, nesse caso, não seria possível não enfrentar a questão visto que de tal estatuto depende a própria definição do objeto. Em outras palavras, o estatuto do discurso, se institucional ou não, só poderia ser definido após a definição da identidade da instância que o produziu.

A saída é, ao que parece, construir uma definição de discurso institucional com base nos instrumentos de que a semiótica e a linguística dispõem, isto é, que esteja alicerçada nos elementos do próprio discurso e que atente para o que o texto afirma de si próprio. Chega-se assim a uma segunda proposta de definição: é institucional o discurso que se apresenta como institucional. Nesse caso, pouco importa quem o produziu, mas sim o que o discurso afirma de si próprio. Uma primeira vantagem de tal definição - ainda que ela possa parecer, à primeira vista, um tanto tautológica - é que ela nos libera da tutela do direito ou de qualquer outra ciência que não as relacionadas ao estudo da linguagem e também da necessidade de ir perguntar alhures o que é uma instituição. Sim, não é tão fácil quanto parece, pois raramente um discurso vem ao mundo proclamando com todas as letras sua índole. Desse modo, a pergunta seguinte (sim, elas continuam a caminhar aos pares) é: como um discurso se afirma como institucional? Agora, contudo, a indagação já não causa embaraços, pois a semiótica pode responder com base apenas em seus conceitos - e será com eles que interrogaremos o discurso. 
Pode-se começar a investigação do ponto em que ela foi abandonada; isto é, indagando se o discurso informa quem o produziu e como o faz. Em termos mais semióticos, a questão é: como a instância da enunciação, isto é a instância produtora do discurso, se projeta no enunciado, logo, no próprio discurso? $\mathrm{Na}$ grande maioria dos textos, há duas opções com algumas variantes: a instância da enunciação pode optar por se projetar no enunciado como o eu que produziu o discurso e, nesse caso, o discurso seria enunciado em primeira pessoa de modo que o momento e o local do suposto ato de enunciação seriam projetados no enunciado e assim se tornariam referências do tempo e do espaço. O tempo seria o agora ou o ontem ou o amanhã ou, enfim, qualquer advérbio de tempo que remetesse ao momento da enunciação, a qual funcionaria como um eixo que articula todo o texto. Nesses casos, afirma-se que houve uma debreagem enunciativa da enunciação, como ocorre nas cartas pessoais ou nos chamados romances em primeira pessoa. No entanto, a instância da enunciação pode optar pela estratégia oposta e não se projetar no enunciado, rompendo, nesse caso, com o momento da enunciação. No enunciado não haverá mais um eu, mas um ele, e os tempos não guardarão mais relação com o ato de enunciação, mas serão o então ou o alhures, como um futuro distante ou mais comumente a indicação de uma data. Também o espaço será indicado sem que se faça referência à enunciação, mediante instalação de um local específico como uma cidade, um país, etc. Em outras palavras, o momento da enunciação deixaria de ser relevante para o entendimento do texto, pois não haveria mais nenhuma referência ao momento de sua produção.

No caso de discursos institucionais, porém, as opções já não são tantas, pois nesse gênero a instância da enunciação não poderia se projetar no texto como um eu, pelo simples fato de que eu não pode ser uma instituição. Não se trata mais de saber o que é uma instituição, mas apenas o que não é, e, para tanto ou ao menos para o caso em questão -, pode-se dispensar o auxílio do direito, dado que é senso comum que um indivíduo isolado não pode ser uma instituição. Imagine-se, por exemplo, uma empresa que se dirige a seus clientes nos seguintes termos: "convido vocês, proprietários dos veículos que fabriquei, a comparecerem a uma de minhas concessionárias..."

Algumas observações devem ser feitas: primeiro, nada impede, embora não seja o mais usual, que o tempo e o espaço sejam projetados no enunciado tomando por referência o momento da enunciação. Por exemplo, uma empresa poderá vir a público retificar uma informação vinculada erroneamente no dia anterior. Nesse caso, poder-se-ia ler algo como: "ao contrário do que foi informado na edição de ontem, neste jornal, o preço da mercadoria $Z$ é $X$ reais e não $Y$ reais...”. Observe-se que o advérbio ontem e o demonstrativo este (em contração com a preposição em) referem-se, naturalmente, à situação de enunciação: ontem só pode ser entendido como o dia anterior a hoje, e hoje é, obviamente, o dia em que se estabelece a comunicação entre enunciador e enunciatário. Outra forma de projeção, mais rara, também é possível. A enunciação poderá projetar-se como um nós coletivo. Isso é mais comum quando o jornal erra e 
informa no dia seguinte o seu erro, em geral com um título como erramos. No entanto, primeiramente deve-se observar que esse nós não é um nós inclusivo (eu e você), mas exclusivo (eu e eles); ou seja, nós, profissionais que trabalhamos neste jornal, erramos... Ou ainda, mais raramente, algo como: nós, os acionistas da empresa tal... Nos dois casos, o nós é utilizado como um substituto de uma coletividade que não inclui o enunciatário e que deve sua existência à instituição envolvida no conteúdo da mensagem: o jornal que cometeu o erro, a empresa que fez o negócio, o sindicato que defende os trabalhadores etc. A terceira observação refere-se ao fato de que o impedimento da projeção do eu no enunciado não alcança o tu. Nada impede, por exemplo, que o tu seja projetado no enunciado, embora este também não seja o caso mais comum. Veja-se um anúncio como: Se você é proprietário do veículo de marca $X$, ano $Y$, dirija-se a uma de nossas concessionárias para... Contudo, também nesse caso, o tu só ganha existência em razão da relação que mantém com a instituição que é a origem do informe. Um último caso, um pouco mais complicado, deve ser mencionado: decretos e regulamentos emitidos por uma autoridade. Nessas situações pode ocorrer o uso da primeira pessoa, porém não de forma isolada da assinatura. Imagine-se um enunciado como: "Eu, fulano de tal, no pleno uso das atribuições que me foram conferidas, determino que..." Primeiramente, deve ser observado que se está entrando no terreno do discurso jurídico, que não é objeto deste estudo e, em segundo lugar, que o pronome eu não se refere propriamente ao indivíduo com seu RG e CPF, mas à autoridade: o prefeito, governador, diretor etc. Tanto é assim, que tanto o nome do cargo quanto o de seu titular devem ser informados e o exercício das funções deve ser legítimo, caso contrário o discurso deixará de ser institucional. ${ }^{1}$

Enfim, embora em um discurso institucional o tempo e o espaço da enunciação possam ser, eventualmente, projetados no enunciado, os actantes da enunciação não poderão fazê-lo como um eu. Talvez seja pouco, mas é mais do que pode parecer. Por exemplo: o discurso literário não sofre essa restrição, obviamente, nem o discurso científico; afinal nada impede o cientista de redigir seus trabalhos em primeira pessoa. Contudo, tal caracterização resolve apenas parcialmente o problema, pois se o critério fosse apenas esse seria dificil distinguir um discurso institucional de outro qualquer não projetasse no enunciado os actantes da enunciação.

A segunda característica do discurso institucional, diretamente relacionada à que se acabou de estudar, é a impossibilidade do anonimato; isto é, a instância da enunciação tem, necessariamente, que ser figurativizada no texto e tem de sê-lo como uma figura do mundo. É importante distinguir essa condição da anterior, pois, à primeira vista, elas podem parecer antagônicas. De fato, a enunciação não pode se projetar no enunciado como um eu, porém tampou-

1 Como a discussão acerca do peso da instituição na eficácia do enunciado extrapola o escopo deste artigo, remetemos os interessados aos trabalhos de Pierre Bourdieu, especialmente à L'économie des échanges linguistiques (1977). 
co pode permanecer desconhecida. Em outras palavras, embora a enunciação não se faça enunciar, o seu ator, isto é, o ator da enunciação deve ser claramente identificado no texto como um ele, e deve parecer verdadeiro, assunto sobre o qual voltaremos em breve. Naturalmente, para a melhor compreensão do que isso significa é preciso conhecer a definição dada pela semiótica para ator e mais especificamente para ator da enunciação. Grosso modo, o conceito de ator pode ser aproximado do de personagem, com a diferença de ser, ao mesmo tempo, mais preciso, pois está relacionado ao nível figurativo de geração do sentido ${ }^{2}$, e mais genérico, pois não está relacionado à idéia de trama ou de personificação. Assim, tanto uma empresa quanto um grilo ou uma varinha mágica podem ser atores, desde que exerçam um fazer. Enfim, para a semiótica um ator é

"o lugar de convergência e de investimento de duas componentes, sintática e semântica. Para ser considerado ator, um lexema deve ser portador de ao menos um papel actancial e de ao menos um papel temático. Acrescentemos que o ator não é somente o lugar de investimento desses papéis, mas também o de suas transformações, uma vez que o discurso consiste essencialmente em um jogo de aquisições e perdas sucessivas de valores." (GREIMAS; COURTÉS 1993, p. 7-8).

Examinando-se a definição acima, percebe-se que para ser classificado como ator um lexema deve preencher os seguintes requisitos:

1) exercer uma função relacionada ao desenrolar da narrativa ou à sua produção (e veremos a seguir que essa segunda alternativa é fundamental);

2) deve ser reconhecível por meio de semas que o associem a um tema: assim o ator será reconhecido como herói, bandido, governo, empresa, sindicato, etc.;

3) deve executar (ou ser objeto de) transformações que constituem a narrativa, uma vez que esta implica, necessariamente, a perda e o ganho de valores, ainda que tais movimentos estejam apenas pressupostos no texto.

Tomando-se por base os três requisitos acima, conclui-se que o ator da enunciação deve, primeiro, ser associado à produção do discurso institucional em questão; segundo, deve ser associado a um tema, no caso, com a execução de uma atividade (governo, comércio, ação não-governamental etc., com todas as especificações possíveis) e, terceiro, deve ser percebido como agente (ou paciente) das transformações de que trata o discurso, as quais, em alguma medida, têm de estar relacionadas ao tema ao qual o ator é associado. A necessidade de identificação inequívoca do ator da enunciação obedece antes de mais nada a coerções de ordem prática: de que adiantaria um discurso institucional que não informasse claramente a instituição que o produziu? Note-se que essa não é uma exigência de outros textos, pois uma denúncia, por exemplo, não precisa identificar seu autor para surtir seus efeitos. Mesmo um texto científico pode prescindir de

2 Não é possível discorrer sobre esses conceitos no espaço disponível. Contudo os interessados poderão conhecê-los mais a fundo em Greimas e Courtés (1993). 
tal informação sem que isso comprometa sua eficácia. Por outro lado, um texto institucional anônimo seria quase uma contradição entre termos.

O ator da enunciação de um discurso institucional tem, enfim, de ser claramente identificado, seja por seu nome, seja por um logotipo, seja por ambos. A preocupação com tal questão é tanta que o uso corrente faz com que a identificação da instituição seja feita tanto no início do texto quanto ao seu final, à guisa de assinatura. Nalgumas vezes tal assinatura pode ficar implícita, desde que não haja dificuldades para identificar o assinante. É o que ocorre quando o jornal apresenta uma nota da redação. Nesses casos, é óbvio que a redação em questão é a do próprio jornal que publica a nota. É também o que ocorre no exemplo citado mais acima, em que o jornal publica um texto com o título Erramos. Também aí está claro que quem errou foi a redação do jornal. Contudo, não basta que a instância da enunciação seja figurativizada; é preciso que ela seja figurativizada como pertencente ao mundo real, pois seria impensável uma nota de uma empresa que fosse assinada por um defunto, como faz Machado de Assis em Memórias póstumas, por um animal, ou por um marciano, enfim, por qualquer entidade que não fosse capaz de produzir o discurso. Pode até ser que a instituição não exista, mas ela tem que causar a impressão da maior normalidade; por exemplo, com indicação de sua razão social, CNPJ etc.

A terceira característica está diretamente relacionada a aspectos sociolinguísticos: o discurso institucional deve necessariamente utilizar a norma culta padrão. Por norma linguística entende-se "um conjunto de realizações linguísticas constantes e repetidas, de caráter sócio cultural” (FIORIN, 1995, p. 82). A norma linguística culta é, portanto, um conjunto de usos reconhecido como correto, segundo a gramática, e detentor de prestígio social perante a sociedade como um todo. A exigência parece estar ligada à própria natureza das instituições, que, de um lado, precisam se apresentar como impessoais, conforme observado quando se discutiu a primeira característica, e, de outro, devem demonstrar que seguem as normas do grupo social - e, nesse caso, nada melhor para seu éthos, isto é, para imagem que constroem de si mesmas por meio de seu discurso, que demonstrar que respeitam as normas e regras vigentes na língua. Nesse contexto, o uso da norma culta contribui para o alcance dos dois objetivos. Note-se, contudo, que não basta que a norma adotada seja correta; é preciso que ela goze de prestígio; não faria sentido, por exemplo, um discurso institucional que tratasse seu destinatário por vós, pois atualmente tal pronome só é utilizado em contextos muitíssimo específicos. Empregá-lo em outras ocasiões seria ridículo. O mesmo efeito desastroso teria um discurso que, no Brasil, adotasse a norma culta de Portugal, pois tal procedimento provavelmente faria com que a instituição em questão fosse associada de forma negativa àquele país. Tal preocupação, porém, não é partilhada pela literatura, que muitas vezes se nutre de tal mecanismo para elaborar seu texto. Por exemplo, a célebre carta que Macunaíma escreve às Icamiabas é toda vazada em uma norma linguística que, já na década de vinte do século passado, era ultrapassada. O resultado é um texto cômico que ri da pretensa modernidade 
da São Paulo das primeiras décadas do século. ${ }^{3}$ Outro exemplo é a obra de Alcântara Machado que escreve os contos de Brás, Bexiga e Barra Funda utilizando a norma dos imigrantes italianos e está aí, justamente, a graça de seu texto. Também o discurso publicitário, de maneira geral, e mesmo o jornalístico (basta que se recorde o famoso Notícias populares, hoje extinto) está livre de tal constrangimento, pois em diversas situações admite-se o uso de gírias e ou de normas que não a padrão. No entanto isso já não está ao alcance do discurso institucional, basta que se pense em um edital de convocação que fosse publicado utilizando a norma empregada por Adoniram Barbosa em seus sambas.

Duas possíveis exceções merecem ser examinadas. A primeira refere-se ao caso de discursos institucionais que vieram a público contendo erros graves de gramática ou ortografia. No entanto, a grande repercussão negativa que tais práticas acarretam basta para mostrar a importância da observância de tal regra, pois se assim não fosse talvez tais deslizes não tivessem o impacto negativo que têm. A segunda exceção refere-se aos sindicatos. Na década de 80 , principalmente, era comum que entidades sindicais produzissem discursos (orais ou escritos) que deliberadamente desrespeitavam a norma culta. No entanto, esta é uma exceção que acaba por confirmar a regra, pois se tratava, justamente, de instituições e movimentos que buscavam colocar em xeque a ordem vigente, e, para tanto, nada mais apropriado que começar a afronta pela língua. Hoje, porém, não havendo mais a mesma preocupação com o confronto, os discursos de tais entidades tendem a se adequar mais à norma vigente. Finalmente, observe-se que mesmo naqueles dias os sindicatos deviam obedecer aos dois requisitos citados acima: não instalar um eu no enunciado e identificar claramente a instituição que o produziu o discurso.

Até agora foram examinadas características do discurso institucional mais ligadas à sua forma, mas é preciso verificar se seu conteúdo guarda alguma peculiaridade. Talvez o primeiro e mais importante requisito do conteúdo de um texto institucional seja seu caráter veridictório: um discurso institucional deve obrigatoriamente parecer verdadeiro, pouco importando se, de fato, é verdadeiro ou não. Ora, para parecer verdadeiro, deve respeitar tanto os requisitos formais, como a identificação do ator da enunciação e o uso da norma culta, por exemplo, quanto aspectos relacionados ao conteúdo, como a apre-

3 Não resistimos à reprodução de um pequeno trecho da carta às Icamiabas "Às mui queridas súbditas nossas, Senhoras Amazonas.

Trinta de Maio de Mil Novecentos e Vinte e Seis

São Paulo.

Senhoras:

Não pouco vos surpreenderá, por certo, o endereço e a literatura desta missiva. Cumpre-nos, entretanto, iniciar estas linhas de saudade e muito amor, com desagradável nova. É bem verdade que na boa cidade de São Paulo - a maior do universo, no dizer de seus prolixos habitantes - não sois conhecidas por "Icamiabas", voz espúria sinão que pelo apelativo de Amazonas; e de vos, se afirma, cavalgardes ginetes belígeros e virdes da Hélade clássica; e assim sois chamadas. Muito nos pesou a nos, imperador vosso, tais dislates da erudiçãa, porém heis de convir conosco que, assim, ficais mais heróicas e mais conspícuas, tocadas por esta platina respeitável da tradição e da pureza antiga [...]." (ANDRADE, 1988, p. 72). 
sentação de um texto coeso e coerente. Por exemplo, o balanço contábil de uma companhia tem que trazer em si as marcas de sua veridicção, tais como o parecer de uma auditoria independente, a indicação dos responsáveis pela sua elaboração e outras informações sem as quais ele não poderá ser aceito, pois lhe cairá a suspeição de falsidade. Naturalmente, essa aparência de verdade não implica ou garante que as informações nele contidas sejam verdadeiras; a recente crise internacional, que teve em seus componentes balanços não de todo honestos, ilustra bem o problema. Aliás, o fato de um balanço conter informações que não são verdadeiras em nada afeta sua natureza. Mesmo mentiroso, ele continuará a ser um discurso institucional. Aliás, se assim não fosse, as eventuais falsificações nele contidas não poderiam acarretar as sanções jurídicas que acarretam. Mais uma vez, essa exigência não se aplica a todos os discursos, naturalmente. Pensemos no caso mais óbvio: a literatura. Evidentemente, não se espera de um texto ficcional que ele seja verdadeiro; ao contrário, sua graça, sua sedução, nasce justamente do fato de ele pertencer à esfera da imaginação, da criação... O mesmo vale para a propaganda. É fato que em última instância as informações por ela veiculadas têm que ser verdadeiras, mas podem não parecer verdadeiras. Por exemplo, tornou-se um lugar comum entre os fabricantes de automóveis apresentarem o ambiente se transformando à medida que o veículo anunciado se desloca em uma paisagem. Ora, evidentemente isso seria impossível e nenhum consumidor sequer considera a possibilidade de isso vir a ocorrer, trata-se de algo que não é verdadeiro. Contudo isso em nada altera a eficácia da propaganda, pois é sabido que o que é apresentado é apenas uma metáfora do conforto e do bem-estar proporcionados pelo automóvel.

Contudo não é assim que as coisas se passam no discurso institucional e a aparência de verdade tem uma importância tal, que discursos que não parecem verdadeiros não poderiam nem mesmo almejar tal classificação, ainda que eventualmente, sejam verdadeiros. Detenhamo-nos um pouco mais sobre essa questão. A semiótica considera que a veridicção resulta das relações lógicas que se estabelecem entre duas modalidades (predicados que podem atuar sobre outros predicados): o ser e o parecer. A representação da gráfica de tais relações, conhecida como quadrado semiótico, permite conhecer melhor todas as implicações

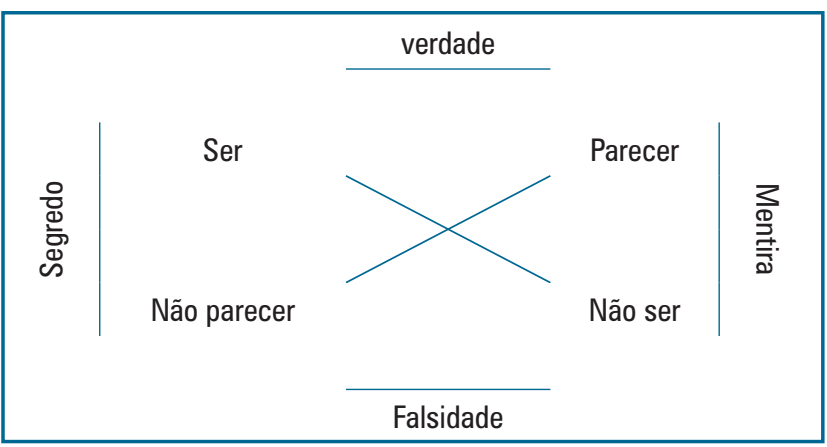


De acordo com o esquema acima, a verdade é uma categoria complexa: é verdade o que parece ser e é verdadeiro. No entanto, se algo é, porém não parece ser, então se trata de um segredo. Por outro lado, é considerado falso aquilo que não parece e não é verdadeiro. Finalmente, e mentira aquilo que parece, mas, de fato, não é verdadeiro. O mundo dos discursos institucionais é marcado justamente pelo parecer; isto é, ele tem que parecer verdadeiro, pouco importando (para a sua definição) se ele é ou não verdadeiro. Assim sendo, tanto discursos verdadeiros quanto mentirosos podem ser institucionais. Por outro lado, os segredos, em razão da obrigatoriedade de publicidade que atinge o discurso institucional, e os discursos falsos, dado que sequer têm a aparência de verdade, não podem ser enquadrados nessa categoria. A questão da aparência pode ainda ser abordada pela pouca (ou quase nula) variação estilística admitida em um discurso institucional, o qual, conforme visto acima, é caracterizado pela impessoalidade, pela formalidade (no caso, pelas marcas de veridicção, como o parecer de uma auditoria independente, no caso de um balanço, ou o logotipo da empresa, em um comunicado oficial) e mesmo pelo pouco ou nulo uso de uma linguagem conotativa, dado que o discurso institucional não pode admitir ambiguidades.

Os critérios definidos até o momento talvez tenham permitido determinar o que não é discurso institucional, mas não foram satisfatórios para definir o que é. Certamente, um discurso que infringir uma das quatro regras acima não poderá ser considerado institucional, mas, por outro lado, o fato de segui-las não lhe confere necessariamente este status. Há vários discursos debreados de forma enunciva, isto é em que a enunciação não é projetada no enunciado, em que a instituição é claramente identificada, que utilizam a norma culta, que parecem ser verdadeiros e que nem por isso são institucionais. Caso típico é o discurso científico, que, no mais das vezes, atende a todos esses requisitos e nem por isso deixa de ser científico e passa a ser institucional. É preciso, portanto, dar um passo a mais em termos de conteúdo e caracterizar definitivamente o que seria discurso institucional, ou, em termos mais simples, determinar do que, afinal, trata esse gênero. É tentador optar pela elaboração de uma relação de todos os possíveis assuntos que poderiam ser abordados, mas, como se sabe, tal procedimento mostrar-se-ia inviável logo no ponto de partida, dada, justamente, a multiplicidade de feições que os discursos institucionais podem assumir: um informe sobre as atividades de uma empresa, a bula de um remédio, o manual que ensina a montar um armário ou que apresenta as normas e procedimentos de uma empresa, a publicação de um balanço ou o pedido de desculpas por uma falha operacional são exemplos de discursos institucionais que fazem parte de uma lista certamente bem mais ampla. Assim sendo, um inventário, por mais extenso que fosse, acabaria por ser incompleto, pouco prático e, provavelmente, incompleto e cheio de incoerências. No entanto, se atentarmos uma vez mais para o ator da enunciação e para as modalidades em jogo é possível que se consiga identificar o que é, afinal, um discurso institucional. Entende-se que em todo discurso institucional há um sincretismo entre o principal actante da enunciação e o principal 
actante do enunciado; ambos devem estar figurativizados no mesmo ator. Em outras palavras, o discurso institucional discutirá, necessariamente, o ser e/ou o fazer do ator da enunciação.

Ao discutir o ser do ator da enunciação (que será também o ator central do enunciado), o discurso institucional apresentará os valores com os quais tal ator encontra-se em conjunção e que, portanto, definem sua identidade. Por exemplo, será abordada sua preocupação com o meio ambiente ou com a justiça social (o que pode ser considerado um dever-ser), sua competência para realizar aquilo a que se propôs (saber-ser), a solidez de suas finanças ou de sua organização (poder-ser) e assim por diante. Por outro lado, o discurso institucional pode abordar o fazer do ator, o qual pode consistir em um fazer pragmático (fazerser) ou um fazer cognitivo (fazer-saber). No primeiro caso, a instituição será mostrada como sujeito que age sobre o mundo e o transforma. Por exemplo, será apresentada como sujeito que luta pela preservação do meio ambiente ou pelos direitos civis, que defende os direitos dos trabalhadores ou dos consumidores, que respeita as minorias, que fabrica os melhores veículos, que emprega milhares de pessoas, que realiza feitos tecnológicos notáveis etc. Entretanto, o fazer do ator da enunciação também pode se limitar a um fazer-saber. É o caso do manual de normas e procedimentos, do manual de instruções, ou da bula do remédio. Pode-se argumentar, porém, que nos dois últimos tipos de documento citados não é o ser ou o fazer do ator da enunciação que estão no centro da cena, mas o ser e o fazer do produto (o remédio, o eletrodoméstico...) acerca do qual são fornecidas instruções. É preciso reconhecer que a questão é controversa, que talvez nem todos os manuais possam ser considerados discursos institucionais e que ainda não se tem uma resposta plenamente satisfatória. No entanto, pode-se pensar que a relação principal que se estabelece nesses textos não é entre comprador e produto adquirido, mas entre enunciador (fabricante) e enunciatário (comprador). Atente-se, por exemplo, para informações sobre cuidado com o uso do produto ou atos que possam acarretar a perda de garantia. Nesses momentos, o que sobressai é primeiramente o papel da instituição que transmite um saber, cujo objeto são as características do produto ou serviço adquirido, e que assim se estabelece um contrato com o enunciatário de garantia de funcionamento, desde que respeitadas algumas regras.

Talvez agora se tenha conseguido delimitar o discurso institucional e determinar sua especificidade. O discurso científico, por exemplo, não discorre sobre o ser ou o fazer do ator da enunciação, no caso, cientista, mas sobre o fenômeno ou objeto estudado. É possível que ao longo do texto se faça referência aos procedimentos adotados pelo cientista para chegar às conclusões a que chegou, mas esse fazer (que também se refere ao ator da enunciação) não é o objetivo último do texto, como ocorre com o discurso institucional, mas simplesmente uma estratégia para garantir que os resultados obtidos sejam confiáveis. Basta pensar em um texto científico que se limitasse a relatar os procedimentos adotados em uma experiência sem nada informar acerca do fenômeno que é objeto de tal experiência. Naturalmente, não faria sentido. 
Examine-se, por fim, o caso da publicidade. Primeiramente, é preciso reconhecer que há uma zona nebulosa na qual os dois tipos de discurso se sobrepõem, pois um texto pode cumprir simultaneamente os dois papéis. Contudo, é preciso recordar que o discurso publicitário não está sujeito aos demais requisitos citados acima, tais como o uso da norma culta, ou a identificação do ator da enunciação. Em seguida, é preciso observar que o discurso publicitário não trata, por definição, da instituição que fabrica o produto ou oferece o serviço, mas do próprio produto ou serviço; se cuidar apenas da instituição, então será institucional, não havendo mais a sobreposição que havia anteriormente entre ator da enunciação e do enunciado.

\section{Considerações finais}

Ao longo deste percurso foram definidos, com a ajuda da semiótica, cinco características que, necessariamente, devem estar presentes em todo discurso institucional, porém nem sempre com o mesmo peso. São elas:

- A enunciação não pode se projetar no enunciado como um eu.

- O ator da enunciação deve obrigatoriamente ser identificado no texto e figurativizado como uma figura do mundo capaz de produzir o discurso em questão.

- Deve ser utilizada a norma culta padrão.

- Deve ser criado um efeito de sentido de verdade; ou seja, o texto produzido deve parecer verdadeiro, independentemente de sê-lo ou não.

- O discurso deve tratar do ser e/ou do fazer do ator da enunciação e por isso haverá um sincretismo entre ator da enunciação e o do enunciado.

Não se considera que essa relação esteja completa ou concluída, pois, conforme citado há pouco, podem existir respostas não de todo satisfatórias, sendo possível que outros critérios surjam ou que os apresentados acabem por ser alterados. Desse modo, as reflexões apresentadas não poderiam (e nem desejariam) ser um ponto de chegada, mas talvez sirvam como ponto de partida para a reflexão acerca de um tipo de discurso que tende a se tornar cada vez mais dominante.

\section{Referências}

ANDRADE, Mário de. Macunaíma o herói sem nenhum caráter. Paris: Association Archives de la Littérature latino-américaine; Brasília: CNPq, 1988.

BORDIEU, Pierre. L'économie des échanges linguistiques. Langue française, Paris, n. 34, mai 1977.

FIORIN, José Luiz. As Astúcias da enunciação. As categorias de pessoa, espaço e tempo. São Paulo: Ática, 1996. . Linguagem e ideologia. São Paulo, Ática 4 ed., 1995.

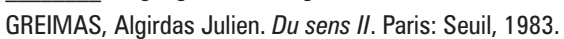

GREIMAS, Algirdas Julien; COURTÉS, Joseph. Sémiotique, dictionnaire raisonné de la théorie du langage I. Paris: Hachette, 1993. SAVIOLI, Francisco Platão; FIORIN, José Luiz. Para entender o texto. 11. ed. São Paulo: Ática, 1995. 